\title{
Preferred Leadership Styles Within Minor League Baseball Organizations' Front Offices
}

\author{
Danny Davis, Ed.D. \\ The University of North Carolina at Pembroke; \\ Pembroke, North Carolina, USA \\ Max Blaisdell Gagnon, M.A. \\ Wilson Tobs; Wilson, North Carolina, USA \\ Leah Holland Fiorentino. D.A. \\ Marian H. Wooten, PhD \\ The University of North Carolina at Pembroke; \\ Pembroke, North Carolina, USA
}

Doi: 10.19044/esj.2017.c1p16 URL:http://dx.doi.org/10.19044/esj.2017.c1p16

\begin{abstract}
Due to the importance of leadership within athletics, this study set out to measure self-reported preference of leadership styles within Minor League Baseball (MiLB) organizations' front offices. The Revised Leadership Scale for Sport (RLSS) was administered to MiLB front office employees at the AAA and AA levels. This instrument previously had been used to measure current athletes' preferences for their coaches' leadership styles. Four hypotheses focused on respondents' preferences for their supervisors' uses of autocratic and democratic leadership styles based on respondents' gender and history with team or individual sport competition. Hypothesis testing revealed only one significant finding, that male front office employees had a higher preference for autocratic leadership style than did female front office employees.
\end{abstract}

Keywords: Revised Leadership Scale for Sport (RLSS), autocratic behavior, democratic behavior, Minor League Baseball (MiLB)

\section{Introduction}

Leadership is an important aspect of successful management that has been the focus of ongoing discussions within the sport business arena for several decades. However, most of the conversations regarding leadership have pertained to the business (working) environment. Only in the past few decades has assessing leadership (coaching) in the sporting industry emerged. This study was designed to examine both the sporting and business sectors by 
surveying AAA and AA front office employees in Minor League Baseball (MiLB) organizations to determine their preferred leadership style. There is limited research on front office employees and as yet, no available discussions of the preferred leadership styles within sport organizations; therefore, no studies have been designed to look at the preferred leadership styles within MiLB organizations' front offices. Previous studies have looked at preferred leadership/coaching styles of collegiate athletes, so by looking at the preferred leadership styles of these employees, it will be determined if sports organizations' employees preferred similar styles to their student-athlete counterparts.

Therefore, the purpose of this study was to determine if former athletes prefer leadership styles similar to their current athletic counterparts through an examination of the preferred leadership styles of employees within MiLB organizations' front offices at the AAA and AA levels. Research about preferred leadership styles is crucial for the efficient operation of front office enterprises and could contribute directly to understanding front office dynamics. The front office of a sport organization is seen as an extension of the on-field product, hence the working relationships among the front office staff can be seen as similar to the workings of the athletic team on the field. Thus, the discourse initiated by and findings from this study will be of interest to all sport organizations and of particular interest to MiLB organizations.

\section{I.}

\section{Leadership styles}

The majority of current research focuses on six main leadership styles. These leadership styles include: autocratic (authoritarian), democratic (participative), laissez-faire, eclectic, Total Quality Management (TQM), and transformational (Quarterman \& Li, 2003; Bucher \& Krotee, 2002; Horine \& Stotlar, 2004).

\section{Autocratic leadership}

The term autocratic can be used interchangeably with "authoritarian" and refers to a task-oriented and leader-centered approach to running an organization or workplace. Horine and Stotlar (2004) described these types of leaders as those who "act like a boss, not a leader" (p. 9). These leaders hold few meetings that allow for little debate; instead a meeting's main function is issuing announcements and directives. This type of leadership is often productive in the armed forces, as well as industrial settings that require uniformity (Horine \& Stotlar, 2004). 


\section{Democratic leadership}

According to Horine and Stotlar (2004), democratic leadership is characterized by the utilization of successful group dynamics strategies in order to run an organization more effectively. Leaders who embrace this style consult with subordinates and groups to gain a consensus on what the group believes is the best course of action. The advantages of using this leadership style include: staff members having their voices and opinions heard; group members collaborating to make programs successful; and eliminating poor ideas by group input (Horine \& Stotlar, 2004).

\section{Laissez-fair leadership}

This leadership style is referred to as "let alone" (Horine \& Stotlar, 2004 , p. 9) because of the low profile that the leader holds to allow the organization to operate on its own. Bucher and Krotee (2002) consider laissezfaire as an extension of the democratic style. Decision-making is made by group members, and little guidance is provided by the person in charge. Typically this style is not recommended because of the actual lack of observable leadership, or the presence of leadership is often not positive; however, this style is successful in some situations, such as allowing new, young leaders to discover new ideas from discussion and obtain experience at a quicker pace than the autocratic style (Horine \& Stotlar, 2004).

\section{Eclectic leadership}

This leadership style is perhaps one of the more desirable because it takes specific situational context into consideration and is also mentioned as similar to the Contingency Theory (Bucher \& Krotee, 2002). Horine and Stotlar (2004) sum up the term best when they state that the eclectic leadership style:

...selects parts of several different forms of administration that will best fit a particular situation. Effective administrators often adopt a democratic style as a cornerstone and mix in needed amounts of the laissez-faire and autocratic approaches as special situations arise. (p. 10)

By using a democratic leadership style as a base and adding autocratic style behaviors secondarily, the leader is able to make the final decision alone (autocratic) even after gathering all the necessary information (democratic).

\section{Total Quality Management (TQM)}

TQM was first discussed by philosopher Deming in the 1950s (Bucher $\&$ Krotee, 2002) and utilizes an extreme dependence on individuals and team work to create continuous improvements throughout an organization (Bucher 
\& Krotee, 2002). TQM leaders put a great deal of responsibility and decision making in the hands of those carrying out a process and those who work directly with the customers (Bucher \& Krotee, 2002; Horine \& Stotlar, 2004). TQM leaders relinquish their authority to well-trained staff that is more knowledgeable in certain fields (Bucher \& Krotee, 2002).

\section{Transformational leadership}

This leadership style centers on the impact of the leader on the organization rather than on individuals or groups within the organization (Quarterman \& Li, 2003). Transformational leadership was a term coined by Bass in 1985 (Bass, 1997) in which "...leaders recognize what followers want and promise to help them get what they want in exchange for support" (p. 21). Transformational leadership is comprised of four main components, or factors: charisma (idealized influence), inspirational motivation, intellectual stimulation, and individualized consideration (Bass, 1997; Quarterman \& Li, 2003).

\section{Measuring leadership in sport}

Measuring the effectiveness of leaders started in the businesses sector and did not move into the sport setting until the 1970s when the effectiveness of coaches became an area of interest (Beam, 2001). According to Zhang, Jensen, and Mann (1997), early primitive measurement tools focused only on measuring sport leadership behaviors rather than considering whether situational characteristics play a role. Some of these early instruments were developed through the Ohio State Leadership Studies (Hemphill \& Coons, 1957; Stogdill, 1948, 1963; Stogdill \& Shartle, 1955, 1956). Other early tools used for measuring sport leadership behavior include the Coach Behavior Description Questionnaire (CBDQ) (Danielson, Zelhart, \& Drake, 1975), the Coaching Behavior Assessment System (CBAS) (Smith, Smoll, \& Hunt, 1977), and the Coach Evaluation Questionnaire (CEQ) (Rushall \& Wiznuk, 1985). The CBDQ and CEQ required student-athletes to identify the behaviors of their coaches within certain leadership categories. In contrast, the CBAS utilized trained individuals to observe and report coaches' behaviors within selected behavioral dimensions. Although these early instruments were useful in measuring the presence of defined leadership behaviors, there was no relevance to the field. The lack of sport-related measuring tools led to the creation of sport-specific instruments that included situational characteristics to better understand leadership behaviors in the sport setting.

\section{LSS and RLSS}

To seek to address the lack of a sport-specific instrument, Chelladurai and Selah (1980) developed the Leadership Scale for Sport (LSS). This 
instrument included five dimensions of leadership behavior: democratic, autocratic, training and instruction, social support, and positive feedback. These five behaviors were sorted into three separate categories: decision-style factors (composed of democratic and autocratic behaviors), direct task factors (composed of training and instruction behavior), and motivational factors (composed of social support and positive feedback factors) (Chelladurai, 1990).

Developed by Zhang et al. (1997), the Revised Leadership Scale for Sport (RLSS) is a more applicable measurement device than the LSS used by the NCAA for intercollegiate student-athletes (Beam, 2001). The RLSS included the addition of two new dimensions: group maintenance behavior and situational consideration behavior. Group maintenance behavior is defined as the way a coach clarifies the relationship among team members, coordinates athletes' activities and improves team cohesion; whereas, situational consideration behavior refers to the way a coach reacts to circumstances based on situational factors (time, the individual involved and environment surrounding the event). Input was collected from intercollegiate coaches, and the instrument was pilot tested by a sample of 696 intercollegiate student athletes from NCAA Division I, II, and III level institutions in Massachusetts and 206 intercollegiate coaches. In its current format, the RLSS consists of sixty items in the following dimensions: democratic behavior (12 items), autocratic behavior (8 items), positive feedback behavior (12 items), situational consideration behavior (10 items), social support (8 items), and training and instruction behaviors (10 items).

\section{Uses of the LSS and RLSS}

A number of researchers have used both the LSS and RLSS to investigate the preferred leadership styles of current student-athletes. The preferences of these student-athletes were compared across two factors of relevance to the present study, gender and type of sport participation-team (i.e., baseball, softball, football, volleyball) or individual (i.e., wrestling, cross country, golf). Table 1 summarizes relevant findings from seven studies. Six of seven studies found that male student-athletes preferred autocratic leadership behaviors more than female student-athletes. In the four studies where team versus individual sport participation was considered, team sport participants preferred autocratic leadership styles more than individual sport participants did. When considering preference for democratic leadership based on gender, past researchers in four studies found that males had a higher preference for this style than did females. Females reported the higher preference in two studies, and the preference of male and female studentathletes did not differ in one study. In the four studies that considered 
individual versus team sport participation, individual sport student-athletes in each of the studies reported a preference for the democratic leadership style.

\section{Methods}

The current study utilized the Revised Leadership Scale for Sport (RLSS) developed by Zhang et al. (1997). The questionnaire utilized a Likert scale ranging from 1(Always)-5 (Never), where a lower score indicated a stronger preference for a leadership style than did a higher score. Respondents used this scale to rate statements pertaining to specific leadership styles. The instrument contained eight statements pertaining to preferences for autocratic behavior and twelve statements pertaining to democratic behavior by leaders. Each statement began with the words "I prefer my supervisor to." Responses to these statements were combined and divided by the number of statements to produce a composite score for preference for autocratic behavior and preference for democratic behavior. In each instance a lower mean score indicated a higher preference for a particular leadership style.

The eight autocratic statements were: Present ideas forcefully, Disregard employee's fears and dissatisfactions, Keep aloof from employees, Dislike suggestions and opinions from the employees, Prescribe the methods to be followed, Refuse to compromise on a point, Plan for the team relatively independent of the employees, and Fail to explain his/her actions. Responses to these autocratic behavior questions were summed and divided by eight to produce a mean score per individual.

The 12 statements to measure preference for democratic leadership style were: Let employees share in decision making and policy formulation, Put the suggestions made by team members into operation, Let employees decide on strategies to be used in a deal, Give the employees freedom to determine the details of conducting a task, Get approval from employees on important matters before going ahead, Ask for the opinion of employees on important leadership matters, Let employees try their own way even if they make mistakes, Ask for the opinion of employees on strategies for specific details, Encourage the employees to make suggestions for ways to conduct work, See the merits of employees' ideas when they differ from the supervisor's, Get input from the employees at daily team meetings, and Let employees set their own goals. Each individual's responses to these statements were summed and divided by 12 to produce a mean score for each individual.

The RLSS was administered as an online questionnaire to the target population--current employees within front offices of MiLB organizations in the United States. The population studied included 60 organizations throughout the contiguous United States. The levels of organizations in the study range from AAA to AA, and 30 teams are represented at each level of 
competition. Front office employees were invited to participate via email, and each team's public website was used to obtain front office employees' email addresses. At the AAA level, 750 employees' email addresses were available (out of 859 total employees), while 558 were available at the AA level (out of 601 total employees). Each employee whose address could be obtained received an initial email with a link to the survey (via Qualtrics). Follow-up emails were distributed twice, and the survey remained open for seven weeks after the initial email distribution.

\section{Results}

Of the 1308 total employees invited to participate, only $96(11.2 \%)$ at the AAA level and $74(12.3 \%)$ at the AA level completed the survey for a total of 170 . Male $(n=112,66 \%)$ respondents outnumbered females $(n=58,34 \%)$. Almost all respondents $(\mathrm{n}=167,98 \%)$ indicated that they had played competitive sports when younger, and within this group 94 individuals (56\%) reported their highest level of competitive sport play to be high school or lower, while $73(44 \%)$ had played college or professional sports. Most respondents $(\mathrm{n}=142,85 \%)$ had played team sports (i.e., baseball, basketball, football, soccer), and the remainder $(\mathrm{n}=25,15 \%)$ had played individual sports (i.e., cross country, track and field, golf, tennis).

New variables were created to be used in hypothesis testing to evaluate preferences for autocratic and democratic leadership styles. The eight statements to assess preference for autocratic leadership style were summed and divided by eight to create a measure for each respondent. The overall mean score for autocratic leadership preference was 3.35. Similarly, each respondent's ratings for the 12 democratic leadership statements were summed and divided by 12 . The overall mean score for preference for democratic behavior was 2.41 .

In order to test the four hypotheses under consideration, independent two sample $t$-tests assuming equal variances were utilized to compare the composite scores across demographic characteristics. The first two hypotheses dealt with the relationship between gender and preference for certain leadership styles; whereas, the third and fourth hypotheses addressed the role of employees' athletic backgrounds (as playing team or individual sports) in their preferences for leadership styles.

The first hypothesis investigated whether or not the gender of front office employees was related to the preference for the democratic leadership style. To test this hypothesis an independent samples t-test was conducted and was not significant, $(\mathrm{t}=0.139, \mathrm{p}=0.889)$, indicating that there was not a relationship between gender and preference for democratic leadership. Indeed, the mean scores for males (2.41) and females (2.42) were nearly identical. 
The second hypothesis considered the relationship between gender of front office employees and preference for autocratic leadership style. To ascertain whether differences existed, an independent samples t-test was utilized. The test was significant $(\mathrm{t}=-3.399, \mathrm{p}<0.001)$, indicating that males working in the front office (mean=3.46) had a higher preference for the autocratic leadership style than did females working in the front office (mean=3.66).

The third hypothesis dealt with the relationship between individual versus team sport background and preference for the democratic leadership style. An independent samples t-test $(t=1.031, \mathrm{p}=0.303)$ revealed that there was no significant difference in preference based on whether an individual had participated in a team or an individual sport. Respondents who played team sports reported a mean score of 2.43 , while respondents who played individual sports reported a mean score of 2.37 .

The final hypothesis examined the relationship between employees' athletic backgrounds (as playing team or individual sports) and preference for the autocratic leadership style. An independent samples t-test was conducted, and results were not significant $(t=0.307, p=0.759)$. Thus, there was no preference for autocratic leadership styles based on whether or not participants had been involved in individual or team sports. In fact, mean scores for respondents who participated in individual (3.55) and team (3.53) sports were nearly identical.

\section{Conclusion}

Discussion

The present study revealed only one significant finding, which was a difference between males and females based on preference for autocratic leadership style. Male front office employees had a higher preference for autocratic leadership style than did female front office employees. Despite the significant different, neither males $(\mathrm{m}=3.46)$ nor females $(\mathrm{m}=3.66)$ expressed a high desire for a supervisor to use this leadership style. On a Likert scale from 1 (Always) to 5 (Never) where 3=Occasionally and 4=Seldom, respondents did not express a strong preference for this style. Results of the present study do confirm findings from previous studies which indicated that male student-athletes exhibited a higher preference for autocratic leadership styles (Beam, 2001; Holmes, McNeil, Adorna, Procaccino, 2008; Suruljal \& Dhurup, 2010; Terry, 1984; Terry \& Howe, 1984; and Witte, 2011).

Hypothesis one, three, and four reveal that respondents did not differ in preference for democratic leadership style based on gender (hypothesis one) or individual versus team sport background (hypothesis three) or preference for autocratic leadership style based on individual versus team background (hypothesis four). Mean responses for each group (gender and type of sport 
participation) tested were slightly more favorable for democratic than for autocratic leadership behavior.

Previous studies examined leadership behavior that current, collegiate student -athletes preferred their coaches utilize; whereas, respondents in the present study were not competing in competitive athletics, and only $44 \%$ of current study population played collegiate or professional sports. Furthermore, the present study asked respondents to consider the preferred leadership styles of their supervisors, not coaches. Relationships between collegiate athletes and their coaches and MiLB front office employees and their supervisors are different in a number of ways, including duration of and expectations from the relationship. Therefore, it is difficult to compare the present study to previous studies. Furthermore, it must be noted that there has not been any previous research within sport organizations and preferences for leadership behaviors based upon the RLSS or LSS.

\section{Implications for future research}

In future research there should be some comparisons with the sport setting and other corporate settings. More research is needed in order to determine if these findings are reliable and repeatable within the same business of sports. While leadership measurement has been studied through the years thoroughly, leadership measurement within the business side of a sport franchise is absent. Furthermore, almost all respondents (98\%) in the present study previously had played competitive athletics at some level. Present perceptions of desirable leadership styles for their supervisors to use may be influenced by the styles respondents' coaches used. A comparison of behaviors preferred in current supervisors and remembered in past coaches may allow future researchers more insights into the leadership preferences of sport organization employees.

\section{References:}

1. Bass, B. M. (1997). Personal selling and transactional/transformational leadership. Journal of Personal Selling \& Sales Management, 17(3), 19-28.

2. Beam, J., (2001).Preferred leadership of NCAA Division I and II intercollegiate student-athletes. UNF Thesis and Dissertations. Paper 166. http://digital commons.unf.edu/etd/166

3. Bucher, C. A., \& Krotee, M. L. (2002). Management of physical education and sport. New York, NY: McGraw-Hill.

4. Chelladurai, P. (1990). Leadership in sports: A review. International Journal of Sport

5. Psychology, 21, 328-354. 
6. Chelladurai, P., \& Selah, S. D. (1980) Dimensions of a leader behavior in sports: Development

7. of a leadership scale. Journal of Sport Psychology, 2, 34-45.

8. Danielson, R. R., Zelhart, P. F., \& Dranke, C. J. (1975). Multidimensional scaling and factor analysis of coaching behavior as perceived by high school hockey players. Research Quarterly, 46(3), 323-334.

9. Hemphill, J. K., \& Coons, A. E. (1957). Development of the Leader Behavior Description Questionnaire. In R.M. Stogdill \& A. E. Coons (Eds.), Leader behavior: Its description and measurement (pp. 6-38). Columbus, OH: Ohio State University.

10. Holmes, R., McNeil, M., Adorna, P., \& Procaccino, J. (2008). Collegiate student athletes'

11. preferences and perceptions regarding peer relationships. Journal of Sport Behavior, 31(4), 338-351.

12. Horine, L., \& Stotlar, D., (2004). Administration of physical education and sport programs. New York, NY: McGraw-Hill.

13. Quarterman, J., \& Li, M. (2003). Managing and leading sport organizations. In J. Parks \& J. Quarterman ( $2^{\text {nd }}$ ed.), Contemporary sport management (pp. 165-183). Champaign, IL: Human Kinetics.

14. Rushall, B. S., \& Wiznuk, K. (1985). Athletes' assessment of the coach: The Coach Evaluation Questionnaire. Canadian Journal of Applied Sport Sciences, 10(1), 157-161.

15. Smith, R.E., Smoll, F. L., \& Hunt, E (1977). A system for the behavioral assessment of athletic coaches. Research Quarterly, 48(2), 401-407.

16. Stogdill, R. M. (1948). Personal factors associated with leadership: A survey of the literature. Journal of Psychology, 25(1), 35-71.

17. Stogdill, R. M. (1963). Manual of the Leader Behavior Description Questionnaire - Form XII. Columbus, OH: Ohio State University.

18. Stogdill, R. M., \& Shartle, C. L. (1955). Methods in the study of administrative leadership. Columbus, $\mathrm{OH}$ : Ohio State University.

19. Stogdill, R. M., \& Shartle, C. L. (1956). Performance profiles of high level positions. In R. M. Stogdill \& C. L. Shartle (Eds.), Patterns of administrative performance (pp. 1-15). Columbus, OH: Ohio State University.

20. Suruljal, J. \& Dhurup, M. (2010). Athlete preference of coach's leadership style. African Journal

21. for Physical, Health Education, Recreation and Dance, 18(1), 111121.

22. Terry, P. C. (1984). The coaching preferences of elite athletes competing at Universiade '83. 
23. Canadian Journal of Applied Sport Sciences, 9, 201-208.

24. Terry, P. C., \& Howe, B. L. (1984). Coaching preferences of athletes. Canadian Journal of Applied Sport Sciences, 9, 188-193.

25. Witte, K. (2011). Coaching leadership preferences: Insight from the National Collegiate Athletic

26. Association Division III athlete. Journal of Coaching Education, 4(2), 73-87.

27. Zhang, J., Jensen, B. E., \& Mann, B. L. (1997). Modification and revision of the leadership scale for sport. Journal of Sport Behavior, 20. 105-121.

Table 1. Summary of Findings from Previous Studies of Student-Athletes' Preferred Leadership Styles

\begin{tabular}{|c|c|c|c|c|}
\hline Researchers & Instrument & Demographic & $\begin{array}{c}\text { Expressed } \\
\text { Higher } \\
\text { Preference for } \\
\text { Autocratic }\end{array}$ & $\begin{array}{c}\text { Expressed } \\
\text { Higher } \\
\text { Preference for } \\
\text { Democratic }\end{array}$ \\
\hline Terry (1984) & LLS & $\begin{array}{c}\text { Gender } \\
\text { Type of Sport }\end{array}$ & $\begin{array}{l}\text { Male } \\
\text { Team }\end{array}$ & $\begin{array}{c}\text { Male } \\
\text { Individual }\end{array}$ \\
\hline $\begin{array}{l}\text { Terry \& Howe } \\
\text { (1984) }\end{array}$ & LLS & $\begin{array}{c}\text { Gender } \\
\text { Type of Sport }\end{array}$ & $\begin{array}{l}\text { Male } \\
\text { Team }\end{array}$ & $\begin{array}{c}\text { Male } \\
\text { Individual }\end{array}$ \\
\hline $\begin{array}{l}\text { Sherman, Fuller, \& } \\
\text { Speed (2000) }\end{array}$ & LLS & $\begin{array}{c}\text { Gender } \\
\text { Type of Sport }\end{array}$ & $\begin{array}{c}\text { Female } \\
\text { Not included }\end{array}$ & $\begin{array}{c}\text { Male } \\
\text { Not included }\end{array}$ \\
\hline $\begin{array}{l}\text { Surujlal \& Dhurup } \\
\qquad(2010)\end{array}$ & LLS & $\begin{array}{c}\text { Gender } \\
\text { Type of Sport }\end{array}$ & $\begin{array}{c}\text { Male } \\
\text { Not included }\end{array}$ & $\begin{array}{c}\text { Female } \\
\text { Not included }\end{array}$ \\
\hline Beam (2001) & RLSS & $\begin{array}{c}\text { Gender } \\
\text { Type of Sport }\end{array}$ & $\begin{array}{l}\text { Male } \\
\text { Team }\end{array}$ & $\begin{array}{c}\text { Male } \\
\text { Individual }\end{array}$ \\
\hline $\begin{array}{l}\text { Holmes, McNeil, } \\
\text { Adorna, \& } \\
\text { Procaccino (2008) }\end{array}$ & RLSS & Type of Sport & Not included & $\begin{array}{c}\text { Female } \\
\text { Not included }\end{array}$ \\
\hline Witte (2011) & RLSS & $\begin{array}{c}\text { Gender } \\
\text { Type of Sport }\end{array}$ & $\begin{array}{l}\text { Male } \\
\text { Team }\end{array}$ & $\begin{array}{l}\text { No difference } \\
\text { Individual }\end{array}$ \\
\hline
\end{tabular}

